\title{
Insights into the morphology of symbiotic shrimp eyes (Crustacea, Decapoda, Pontoniinae); the effects of habitat demands
}

Nicola C Dobson, Magnus L Johnson, Sammy De Grave

Morphometric differences in the optical morphology of symbiotic palaemonid shrimps can be observed among species symbiotic with different host organisms. Discriminant functional analysis revealed three distinct groups within the species examined. Of these, bivalve symbionts appear to have an eye design that is solely unique to this host-symbiont grouping, a design that spans across multiple genera of phylogenetically unrelated animals. Although some taxonomic effects may be evident, this does not explain the difference and similarities in eye morphology that are seen within these shrimps.

Therefore evolutionary pressures from their host environments are having an impact on the optical morphology of eyes however, as indicated by host-hopping events there ecological adaptations occur post host invasion. 
1 Insights into the morphology of symbiotic shrimp eyes (Crustacea, Decapoda, Palaemonidae); the effects of habitat demands

\section{Nicola C. Dobson ${ }^{* 1}$, Magnus L. Johnson ${ }^{1}$ \& Sammy De Grave ${ }^{2}$}

$4{ }^{1}$ Centre for Environmental and Marine Sciences, University of Hull, Scarborough Campus, Filey

*Corresponding author: n.dobson@biosci.hull.ac.uk

\section{Abstract}

9 Morphometric differences in the optical morphology of symbiotic palaemonid shrimps can be

10 observed among species symbiotic with different host organisms. Discriminant functional

11 analysis revealed three distinct groups within the species examined. Of these, bivalve symbionts

12 appear to have an eye design that is solely unique to this host-symbiont grouping, a design that

13 spans across multiple genera of phylogenetically unrelated animals. Although some taxonomic

14 effects may be evident, this does not explain the difference and similarities in eye morphology

15 that are seen within these shrimps. Therefore evolutionary pressures from their host environments

16 are having an impact on the optical morphology of their eyes however, as indicated by host-

17 hopping events there ecological adaptations occur post host invasion. 


\section{Introduction}

19

Symbiotic palaemonid shrimps are widespread and abundant in Indo-West Pacific reefal habitats, characterised by their affinity to form associations with a wide range of taxa. Until recently these shrimps were in the subfamily Pontoniinae. However in a recent phylogenetic study by De Grave et al., (2015) this subfamily was synonymised with the family Palaemonidae, as were the related families Gnathophyllidae and Hymenoceridae. For the purposes of this investigation and throughout the remainder of this paper, we will refer to this group of shrimps as 'pontoniine shrimps' to avoid any systematic ambiguity. Members of the previously separate families Gnathophyllidae and Hymenoceridae were not included in the present analyses. Within the pontoniine shrimps, an estimated 60-70\% (De Grave, 2001) are known to form associations with corals, sponges, ascidians, gorgonians, and so on. However this is likely to be an underestimate as the host association remains unknown for several species, but is inferred to be symbiotic due to their morphological similarity to other species. Pontoniine shrimps occur in a wider variety of tropical and subtropical habitats, and are known from deeper water, down to about $2000 \mathrm{~m}$ (Bruce, 2011). However, their highest species richness is on tropical coral reefs, down to about $100 \mathrm{~m}$. The most recent catalogue (De Grave \& Fransen, 2011) lists 602 species, but numerous species have been described since then.

The traditional view of these shrimps as symbionts has recently been challenged for a number of species dwelling in sponges, where diet studies revealed them to be parasites as their stomachs only contained host tissue and spicules (Ďuriš et al., 2011). At present it is not known how widespread parasitism is in the group, and we thus refer to them as associates, inferring no trophic interaction with the host.

Morphological adaptation to an associated mode of life has been extensively noted in the taxonomic literature for pontoniine shrimps. Such adaptations include modified pereiopods (Bruce, 1977; Patton, 1994) in addition to extensive modifications in general body plan and mouthparts (Bruce, 1966; Ďuriš et al., 2011). Additionally, a range of ecologies are recognised, ranging from internally dwelling in small sized hosts like ascidians (e.g. species of the genus Periclimenaeus) to fish cleaning species, dwelling on anemones (e.g. Ancylomenes spp.). Despite this wealth of morphological and ecological disparity, few studies have been done linking morphological disparity with ecological constraints. A recent exception to this is the study by Dobson et al (2014) which examined gross eye morphology across four, broad, lifestyle 
49 categories: ectosymbionts, bivalve endosymbionts, non-bivalve endosymbionts, and free-living.

50 Their results clearly demonstrated considerable differences in superficial optical parameters

51 across various lifestyles. In many decapods, vision is thought to be an important feature of their

52 morphology with variations in morphology and structure reflecting ecological habitat demands

53 (Johnson, Shelton and Gaten, 2000). Differences in eye size, facet size and interommatidial angle

54 have been observed in many marine species occupying different depths (Gaten, Shelton, and

55 Herring, 1992; Johnson et al., 2000). Eye parameter (EP) has been used by a number of

56 researchers as a measure of determining the equipoise between sensitivity and resolution of

57 different organisms (Snyder, 1979; Stavenga \& Hardie, 1989; Kawada et al., 2006). For

58 organisms occupying well-lit habitats EPs of between 0.45 and $1 \mathrm{rad}-\mu \mathrm{m}$ have been recorded, 1-2

59 for crepuscular and 2-3 for nocturnal species (Kawada et al., 2006), however these values many

60 vary in aquatic organisms due to the different refraction index of water. Pontoniine shrimps are

61 ideal study organisms for the relationship between eye morphology, vision and habitat demands,

62 given their predilection for forming associations with a wide range of taxa.

63 The current study builds upon this previous work by focussing on and contrasting across actual

64 host identities using a multivariate analytical framework and thus aims to further unravel

65 potential differences in gross optical morphology of pontoniine shrimps.

\section{2. Methods}

67 Optical characteristics of 96 species from 40 genera were examined from collections at the

68 Oxford University Museum of Natural History. A copy of the dataset used in this paper can be

69 accessed in the Supplemental Information. The work described in this paper was reviewed and

70 approved by the Department of Biological Sciences, Faculty of Sciences ethics committee

71 approval number U053. To understand differences in eye morphology between host categories,

72 each species was classed into host-symbiont predefined groupings based on their most common

73 host associations (Bruce, 1994); i.e. Actiniaria, Ascidiacea, Asteroidea, Bivalvia, Crinoidea,

74 Echinoidea, Gorgonacea, Hydrozoa, Ophiuroidea, Porifera and Scleractinia or considered to be

75 free-living. For all species, eye span (ES), diameter at the base of the eyestalk (DBES), facet

76 diameter (FD) and eye diameter (ED) were measured using a dissecting microscope fitted with an

77 ocular micrometer. To reduce scaling effects ES, DBES and ED were standardised by post orbital

78 carapace length, whilst FD was standardised by eye diameter. A composite variable, ES-DBES

79 (eye span minus diameter at base of eyestalk), was also formulated to provide an indication of 
80 eye mobility, the greater mobility of the eyes the larger the value. In addition to the variables

81 measured, eye parameter (EP) was calculated as an outcome of facet diameter $(\mu \mathrm{m})(\mathrm{FD})$ and

82 interommatidial angle ( $\Delta \varphi$ in radians) using Snyder (1979) equation (Equation 1).

83 Equation 1.

$$
E P=F D \Delta \varphi
$$

84 Interommatidial angle in radians, used in the calculation of EP, was estimated using an adaptation 85 of Stavenga's (2003) formula (Equation 2).

86 Equation 2.

$$
\Delta \varphi=2\left(\frac{F D}{E D}\right)
$$

87 The presence or absence of the nebenauge (see Dobson et al., 2014) was also noted and when 88 present the relative size was expressed after standardisation by eye diameter (ED). Our terminology follows Johnson et al. (2015), who utilised 'nebenauge' for the structure previously referred to under several names.

91 Eye Parameter (EP) and standardised nebenauge size was compared between hosts using a 92 Kruskal Wallis test in the Statistical Software Package R 3.0.2 as this allowed for Post Hoc 93 comparisons (R Core Team, 2013), whilst Eye Diameter (ED) was analysed by the means of an 94 ANOVA.

95 Subsequently, the dataset was analysed with Discriminant Function Analysis (DFA), also known 96 as Multiple Discriminant Analysis (MDA) or Canonical Variate Analysis (CVA). DFA extracts

97 linear combinations of variables (known as roots) which maximise differences amongst a priori 98 defined groups, in this case host categories, with the percentage correctly classified providing a 99 goodness of fit measure, akin to more traditional $\mathrm{P}$ values.

100 As DFA requires the number of predictor variables to be fewer than the sample size of the 101 smallest group, a number of host-categories could not be included in the analysis, namely 102 Echinoidea, Hydrozoa, Ophiuroidea and Asteroidea, all of which are relatively infrequently 103 inhabited by pontoniine shrimp. Outliers were identified using within host category linear least104 squares regression analysis, using post-orbital carapace length as the independent variable. 
105 Individual outliers were corrected by re-measurement (where possible), and only excluded from

106 the final dataset if their values still exceeded 3 standard deviation in residual plots. The final

107 dataset analysed with DFA thus comprised of 83 species, across 7 host categories, as well as free-

108 living taxa. Host categories herein analysed, comprise of Actiniaria (9 shrimp species),

109 Ascidiacea (7), Bivalvia (12), Crinoidea (8), Gorgonacea (7), Porifera (14) and Scleractinia (13).

110 Thirteen micro-predatory species, which are currently considered not to be host associated, i.e.

111 free-living were also included in the analysis, a combination of species living on coral reefs and

112 in seagrass beds. The full species names of the 83 species examined in the DFA analysis are not

113 included on any of the DFA plots however these can be found the Supplemental Information.

114 For consistency, statistical analysis of eye size, Eye Parameter and nebenauge was carried out on

115 the reduced dataset.

116 Prior to DFA, proportions were arcsine-transformed to meet the assumptions for statistical

117 analysis of normality and homogeneity (Zuur, Ieno and Elphick, 2010). All DFA analysis was

118 performed in SPSS 18. In all DFA analysis, all variables were entered simultaneously, with the

119 contribution of each variable assessed on the basis of discriminant loadings (structure

120 correlations, rather than discriminant coefficients, as those are considered more valid when

121 interpreting the relative contributions of each variable).

\section{$122 \quad 3 . \quad$ Results}

\section{$123 \quad 3.1 \quad$ Eye size, Eye Parameter and nebenauge presence}

124 Across all species examined, mean relative ED (Fig. 1) ranged from 0.09 to 0.27 , with

125 significantly smaller eyes occurring in bivalve associated species (ANOVA, $\mathrm{F}_{7,75}=9.26, P<0.001$,

126 Tukey $P=0.05)$. Although the analysis deemed none of the remaining differences to be

127 statistically significant, ascidian $(\bar{x}=0.19, S D \pm 0.06)$ and sponge symbionts

$128(\bar{x}=0.19, S D \pm 0.06) \quad$ were also found to possess some of the smallest relative EDs whilst

129 gorgonian symbionts $(\bar{x}=0.28, S D \pm 0.11)$ and free-living shrimps $(\bar{x}=0.26, S D \pm 0.06)$ had 130 the largest relative EDs. 
131 Eye parameter (EP) (Fig. 2) ranged from $0.44-8.06$ rad- $\mu \mathrm{m}$, with a significantly larger EP found

132 in ascidian, bivalve and sponge associates (Kruskal Wallis, $\mathrm{H}$ (adjusted for ties) $=43.62, \mathrm{df}=7$,

$133 P<0.001$, Post hoc pairwise comparisons $P=0.05)$. The smallest EP values were found in

134 associates of crinoid, gorgonians and in free-living shrimps. Associates of sea anemones and

135 corals were not significantly different to any other host category in terms of EP (Fig. 2), whilst

136 the widest range of values is present in sponge associates. Although not statistically considered as

137 outliers in within-host category regression analysis, three species exhibited an aberrant EP, all of

138 the genus Pontonia. Pontonia panamica an ascidian commensal has the largest EP in the dataset

139 (EP = 7.45), whilst P. mexicana and P. pinnophylax exhibited considerable larger values than

140 other species associated with bivalves.

141 A significant association was found between the presence/absence of the nebenauge and host 142 category (Chi-squared test, $\chi^{2}=24.777$, $\mathrm{df}=7, P<0.001$ ). High absence rates of the nebenauge

143 were observed among ascidian, bivalve and poriferan symbionts (Fig. 3), whilst it is prevalent in

144 sea anemone associates and free-living shrimps. However, the relative size is not different across

145 host categories (Kruskal Wallis test, $\mathrm{H}=8.93, \mathrm{df}=6, P=0.178$ ), with ascidians excluded as only

146 one species, Periclimenaeus hecate, had a nebenaugen.

\section{$147 \quad 3.2 \quad$ Multivariate analysis}

148 Discriminant function analysis revealed only two significant roots (Table 1), which cumulatively 149 explain $94.6 \%$ of total variance. Examination of the structure matrix (Table 2) revealed that three 150 variables were highly loaded on to the first root (EP, FD, ED), whilst a fourth variable (ES-

151 DBES) displayed greatest loading on the second function.

152 A classification matrix indicates that overall 50.6\% of shrimp species were correctly classified in 153 respect to their priori defined groups (host classification) (Table 3), but with significant variation 154 as to within-group classification. Bivalve associates were $100.0 \%$ correctly classified, with a high 155 number also correctly classified for sponge associates (78.6\%). Over half of the free-living 156 species (61.5\%) were correctly classified to their priori group, with other species classified as sea 157 anemone, crinoid and coral associates. Gorgonian associates correctly classified in 42.9\% of 158 cases, with misclassified taxa allied to free-living, coral and crinoid associates. Coral associates 159 correctly classified in $38.5 \%$ of cases with species misclassifying as associates of sponges, sea 
160 anemones, crinoids and free-living species. Sea anemone and crinoid associates were only 22.2

161 and $25.0 \%$ correctly classified. All ascidian symbionts were found to misclassify, with $71.4 \%$ of

162 them misclassified as sponge associates.

163 When comparing the relative position of the centroids for each host category (Fig. 4) it is

164 obvious, that the eyes of ascidian and sponge associated species are very similar to each other, as

165 are the eyes of crinoid and coral associates, both of which also group with the free-living species.

166 Although broadly similar to the latter grouping, the eyes of gorgonian and sea anemone

167 associates are somewhat divergent as well as divergent to each other, as evidenced by the position

168 of their centroids. Bivalve associates clearly occupy an isolated position, relative to the other

169 host categories.

170 When plotting only the ascidian associates in the DFA analysis (Fig. 5), a divergent position of $P$.

171 panamica is evident, whilst the other taxa form a loose grouping. The positions of sponge

172 associates (Fig. 6) reveal two distinct, but loose groupings, as well as a divergent species,

173 Thaumastocaris streptopus. Membership of either of the two groups does not appear influenced

174 by phylogeny, as either group contains species belonging to the genera Typton and

175 Periclimenaeus. The positions of the individual bivalve associates (Fig. 7) reveals a relatively

176 tight grouping, but with an isolated position occupied by Conchodytes nipponensis. The

177 positions of individual crinoid associates (Fig. 8) are rather scattered, but with a very isolated

178 position for Laomenes nudirostris. A similar scattered pattern is observed for the coral associates

179 (Fig. 9) and the free-living species (Fig. 10). Gorgonian associates also demonstrate this pattern

180 (Fig. 11), but with a significant, isolated position for Pontonides loloata. A similar pattern is

181 observed for sea anemone associates (Fig. 12), with an isolated position for Periclimenes

182 scriptus.

\section{4. Discussion}

184 Multivariate analysis clearly reveals that three distinct eye types are present in pontoniine

185 shrimps, with bivalve associates comprising a type on their own. Sponge and ascidian associates

186 have remarkably similar eyes, to the point that the majority of ascidian associates were

187 misclassified as sponge associates in the analysis. A third eye type is present in a range of 
188 ectosymbiotic taxa, associated with sea anemones, gorgonians, corals, crinoids, as well as free-

189 living species.

190 An examination of the structure loadings reveals that along the first root, both facet diameter

191 (FD) and Eye Parameter (EP) increases, but with a concomitant decrease in eye diameter (ED),

192 whilst along the second root eye mobility (as measured by ES-DBES) decreases. Broadly

193 speaking, the ectosymbiotic and free-living taxa thus have smaller facet diameters, a lower EP

194 and bigger eyes, than their endosymbiotic counterparts in bivalves, sponges and ascidians.

195 Equally, bivalve associates display more mobile eyes than ascidian and sponge associates, but

196 with roughly similar facet diameter and EP. It should be noted that the relative eye size of

197 bivalve associates is significantly smaller than all other host groupings, this may be as a result of

198 their comparably larger body sizes (e.g. mean average $6.9 \mathrm{~mm}$ CL versus $3.0 \mathrm{~mm}$ CL for

199 Actiniaria, $2.5 \mathrm{~mm}$ CL for Porifera and 1.34 mm CL for Gorgonacea symbionts).

200 Within deep sea caridean species the nebenauge has been suggested to have an important role in

201 diurnal migrations (Johnson et al., 2015). The concept that orientation to light is aided by the

202 presence of the nebenauge is further supported by these results with it being highly abundant

203 within sea anemone, crinoid, free-living and coral associates. However for bivalve, ascidian and

204 sponge associates both diurnal migrations and orientation to light would be of little significance

205 for species with an endosymbiotic mode of life.

206 This result is not surprising, given the clear relationship between gross eye morphology of

207 pontoniine shrimps and life style already demonstrated in Dobson et al. (2014). Therein, based on

208 a range of optical parameters, the eyes of free-living and ectosymbiotic species were found to be

209 very similar, and clearly different from both types of endosymbiotic species considered, bivalves

210 and non-bivalve associates. Further, bivalve endosymbionts exhibited an intermediary group

211 between free-living/ectosymbionts and non-bivalve endosymbionts, potentially linked to their

212 presumed more active lifestyle, with bivalve associated documented to move hosts in search of a

213 mate (Baeza et al., 2011).

214 Whilst the relationships between optical parameters and lifestyle in Dobson et al. (2014) appears

215 clear-cut and supported by the present analysis, by including actual host identity, rather than

216 lifestyle in the current analysis, a number of surprising findings emerge. 
217 The eyes of ascidian associated species emerges as being remarkable similar to the eyes of

218 sponge associated species, to the point that the majority of a priori classified species in this group

219 were misclassified as sponge eyes by the multivariate analysis. This is herein interpreted being

220 likely a significant signal of phylogenetic constraint, as four out of the seven species in this host

221 category belong to a primarily sponge dwelling genus, Periclimenaeus (see below) with generally

222 conservative eye morphology, potentially indicative of recent host switching event(s). Two

223 further species in this host category, phylogenetically unrelated to Periclimenaeus, Dactylonia

224 okai and Odontonia katoi are thought to be closely related species (Fransen, 2002), but with

225 significantly different gross eye morphology. Dactylonia okai possesses stout triangular shaped

226 eyes, whereas the eyes of Odontonia species are small and hemispherical (Fransen, 2002).

227 Whilst D. okai and $O$. katoi are found living within large solitary ascidians, species of

228 Periclimenaeus are found living within both ascidians and sponges. Species such as

229 Periclimenaeus orbitocarinatus and Periclimenaeus ascidiarum live in association with

230 compound ascidians that are structurally similar in morphology to the canals of sponges occupied

231 by, for example, Periclimenaeus maxillulidens. The structural similarity in hosts between the

232 symbionts of compound ascidians and sponges could be a plausible explanation for the high

233 misclassification of ascidian symbionts to sponges. Two species were misclassified as either a sea

234 anemone or bivalve associate. Although DFA does not provide information on individual

235 classified species, it is evident from Fig. 5 that P. panamica is the species misclassified as a

236 bivalve associate. The genus Pontonia comprises of 11 species (De Grave \& Fransen, 2011) and

237 is morphologically very conservative. Although the host for one species, P. longispina, is not

238 known, the majority of species associate with bivalves in the families Pinnidae and Pteriidae,

239 whilst one poorly known species P. chimaera, is thought to be an associate of large gastropods of

240 the genus Strombus. Pontonia panamica is the only species to associate with ascidians, the

241 solitary species Ascidia interrupta in the eastern Pacific. Although Marin and Anker (2008)

242 speculate that a host switch to ascidians occurred early on in the evolutionary history of this

243 genus, the retention of essentially a "bivalve" eye is perhaps indicative of a more recent host

244 switching event. However, on balance the differences in eye morphology between the

245 phylogenetically not related genera herein analysed as ascidian associates suggests that despite

246 occurring in a similar host environment, their enclosure inside ascidians has not provided

247 pressure on their eyes to become optically similar. As to whether this lack of overall evolutionary

248 pressure is imparted by distinctive host morphologies (compound, solitary) or habitats (intertidal, 
249 subtidal) or indeed is determined by differential behavioural attributes (social biology) of the 250 associates themselves remains unclear.

251 Notwithstanding their close similarity to ascidian associate eyes, the eyes of sponge associated 252 species appear to be quite uniform, with the majority being correctly classified in their a priori 253 defined host group, but seemingly forming two distinct subgroups in the analysis, in addition to 254 the outlying T. streptopus. We infer here that the classification into two subgroups is putatively 255 related to host morphologies, as sponge species exhibit a discrete and distinct range of canal 256 sizes. Space partitioning, as well as individual host selection is indeed known to play a 257 significant role in the sponge-dwelling gambarelloides group of Synalpheus (Duffy, 1992;

258 Hultgren and Duffy, 2010; 2012). The speculation that canal sizes of the host may play a 259 significant role in optical acuity of pontoniine species, can however not be substantiated, as the 260 host range of most species remains unknown, with even the identity of many hosts simply not 261 being known. For instance, for many species of Periclimenaeus, a primarily sponge associated 262 genus, the hosts are not known (Bruce, 2006). Of particular interest are the three ectosymbiotic 263 species included in this primarily endosymbiotic group in the present analysis, T. streptopus,

264 Periclimenes harringtoni and Periclimenes incertus. Thaumastocaris streptopus is an Indo-

265 Pacific species, which dwells in the central atrium of vase-shaped sponges like Siphonochalina 266 and Callyspongia (see Bruce, 1994). Based on the present suite of optic parameters, this species 267 does not cluster with the rest of the sponge associates. Although Duriš et al. (2011) consider the 268 species to be parasitic, in common with several other sponge associates, the isolated position of the species in the present analysis, combined with their asymmetrical first pereiopods and a segmented carpus (both unique within the family) is indicative perhaps of a different behavioural niche. The Indo-Pacific, $P$. incertus dwells on the outside of a variety of sponges, and clusters reasonably close to the other sponge associates in the present analysis, potentially indicative of similar relationship to the host, if external. The Caribbean $P$. harringtoni dwells in the atria of Neofibularia nolitangere and based on the optical parameters studied herein, appears to have an eye structure very similar to that of endosymbiotic species, potentially an example of habitat driven adaptation, despite the significant difference in position on the host. The sea anemone associates included in the present analysis, fall into four ecological/systematic groups, Ancylomenes and three different species groups of Periclimenes. Ancylomenes species are on the whole considered to be fish cleaners, who only utilise the sea anemone as an advertisement 
280 for their services to client fish (Huebner \& Chadwick, 2012). It should be noted that this is

281 potentially a generalisation, as direct observation of fish cleaning behaviour is not available for

282 all species, with this information lacking for one species herein included A. tosaensis.

283 Periclimenes yucatanicus and Periclimenes rathbunae are active large bodied species, associated

284 with a variety of sea anemones in the Caribbean. Fish cleaning has not been observed for either

285 species, with Limbaugh et al., (1961) considering P. yucatanicus a fish-cleaning mimic.

286 Periclimenes ornatus and P. inornatus belong to the same species complex, and are smaller

287 bodied species which hide in between the tentacles of a variety of Indo-Pacific sea anemones.

288 Finally, P. scriptus, a Mediterranean and subtropical Northeast Atlantic species which is not

289 phylogenetically closely related to the other two groups, is an active species, associated with long

290 tentacle sea anemones, with no known fish cleaning behaviour. With the exception of P. scriptus

291 (see below) these species exhibit a scattered grouping in the DFA analysis, and as a group have a

292 low percentage correctly classified, at $22 \%$. It thus appears that despite their broad ecological

293 niche similarity as sea anemone associates, insufficient convergent pressure on their optical

294 parameters is noted, indicative of differential usage of their eyes.

295 In contrast to sea anemone associates, coral associates exhibit a reasonable level of correctly 296 classified in the DFA analysis, at 38.5\%, despite the large variety of host morphotypes involved

297 in this association. Several species including Coralliocaris spp., Harpilius spp. and, Harpiliopsis

298 spp. are associated with branching corals of the families Pocilloporidae and Acroporidae. Other

299 species in this group are associated with corals that extend their polyps during the day, depending

300 of the species of coral these polyps can be with short or long in size. Examples of species

301 inhabiting these hosts include Hamopontonia corallicola found within the short polyps of

302 Goniopora and Cuapetes kororensis that dwells within the long polyps of Heliofungia

303 actiniformis. Morphologically heavily modified taxa are also present in this group, such as the

304 laterally flattened Ischnopontonia lophos which moves between the corallites of Galaxea. It thus

305 appears that the habitat and/or behaviour in the case of coral associates is a significant driver in

306 optical parameters, akin to the free-living species, which had an approximately similar level of

307 correctly classified species (53.8\%). However, in contrast to free-living taxa, which are

308 considered to be micro-predators, several of the coral associates are potentially parasites (Stella

309 et al., 2011). The common functionality of their optic parameters (to a degree) remains unclear,

310 although it is known that several species, e.g. Coralliocaris defend their coral host against 
311 predators (Marin, 2009a; Stella et al., 2011), perhaps necessitating the need for similar optical

312 acuity to free-living micro predators.

313 Bivalve associates exhibited a 100\% correct classification in the DFA analysis, although with

314 reasonable scatter in the scatter plot, and a significant outlier (C. nipponensis). Yet the group

315 consists of several genera, including Conchodytes and Anchistus, which are phylogenetically

316 distant (Kou et al., 2014). Furthermore these species can be differentiated by general bauplan

317 morphologies, ranging from relatively unspecialized (Anchistus and Paranchistus for example) to

318 dorso-laterally compressed (e.g. Conchodytes) (Bruce 1981; Fransen \& Reijnen, 2012). Their

319 phylogenetic distance is evidence of multiple host invasions (Kou et al., 2014), but the present

320 analysis reveals considerable convergence in optical parameters, indicative of profound habitat

321 induced restraints.

322 A number of species occupy isolated positions within their respective groups, notably P. loloata,

323 P. scriptus, C. nipponensis and L. nudirostris. Although we cannot discount variation in optical

324 parameters of individual eyes, which may have lowered the percentage correctly classified and

325 induced a higher degree of scatter, two species are worthy of further discussion. The corneal part

326 of the eye of Laomenes species is characterised by an apical papilla (see illustrations for several

327 species in Marin, 2009b) which contains functional facets, but which are somewhat different in

328 shape to facets elsewhere on the cornea. The relative size as well as the exact position of the

329 papilla has been used as a minor taxonomic character to differentiate between species (Marin,

330 2009b). However, it is known that a large degree of infra-specific variation is present, which

331 unquestionably would influence some of the herein included optical parameters. Periclimenes

332 scriptus appeared isolated within the sea anemone grouping however due to the small size of the

333 specimen (CL $1.25 \mathrm{~mm}$ ) it is possible that this animal was not fully mature as ovigerous females

334 have a reported CL of $5.0 \mathrm{~mm}$ (Ďuriš et al., 2013).

\section{5. Conclusions}

336 Overall, our analysis demonstrates that there is a significant evolutionary pressure of the host

337 environment on the optic parameters of associate shrimp species, with in many cases congruence

338 being evident between phylogenetically unrelated taxa. This is especially evident in bivalve and

339 sponge associates, and to a lesser extent in other host taxa. This result is in sharp contrast to the 
340 disparate morphology of many other body parts of pontoniine shrimps, with significant variation

341 in mouthparts, pereiopods and even general body shape between genera, inhabiting the same

342 host. At the same time, evidence emerges from the optical analysis of recent host switching

343 events in certain lineages, where the optical parameters have not evolved to a communality yet,

344 especially in the genera Periclimenaeus and Pontonia, where taxa living in different hosts appear

345 to retain a close optical similarity to those living in other taxa.

\section{6. Acknowledgements}

347 We would like to thank Dr Sue Hull for her valuable suggestions with regards to the analysis and

348 comments on previous versions of the manuscript. We would also like to thank both reviewers for

349 their valuable comments on the manuscript.

\section{$350 \quad 7 . \quad$ References}

351 Baeza, J.A., Bolaños, J.A., Hernandez, J.E., Lira, C. \& López, R. 2011. Monogamy does not last

$352 \quad$ long in Pontonia mexicana, a symbiotic shrimp of the amber pen-shell Pinna carnea from

353 the southeastern Caribbean Sea. - Journal of Experimental Marine Biology and Ecology

$354 \quad$ 407(1): 41-47.

355 Bruce, A.J. 2011. A new record of Periclimenes pholeter Holthuis, 1973 (Crustacea: Decapoda:

356 Pontoniinae) from the Red Sea. - Cahiers de Biologie Marine 52(1): 119-120.

357 Bruce, A.J. 2006. Periclimenaeus nielbrucei sp. nov. (Crustacea: Decapoda: Pontoniinae), a new

358 sponge associate from the Capricorn Islands, Queensland, with notes on related

359 Periclimenaeus species. - Zootaxa 1224: 1-22.

360 Bruce, A.J. 1994. A synopsis of the Indo-West Pacific genera of the Pontoniinae (Crustacea:

361 Decapoda: Palaemonidae). - Theses Zoologicae 25: 1-172.

362 Bruce, A.J. 1981. Notes on some Indo-Pacific Pontoniinae, XXXVI. Pontonia ardeae sp. nov., a

363 new bivalve associate from the Capricorn Islands (Decapoda, Natantia). - Crustaceana 40(2):

$364 \quad 113-126$.

365 Bruce, A.J. 1977. The hosts of the coral associated Indo-West Pacific Pontoniine shrimps. - Atoll

366 Research Bulletin 205: 1-19. 
367 Bruce, A.J. 1966. Notes on some Indo-Pacific Pontoniinae. XI. A re-examination of Philarius

368 lophos Barnard, with the designation of a new genus, Ischnopontonia. - Bulletin of Marine

$369 \quad$ Science 16(3): 584-598.

370 Dobson, N.C., De Grave, S. \& Johnson, M.L. 2014. Linking eye design with host symbiont

371 relationships in pontoniine Shrimps (Crustacea, Decapoda, Palaemonidae). - PloS ONE 9(6):

372 e99505.

373 Duffy, J.E. 1992. Host use patterns and demography in a guild of tropical sponge-dwelling 374 shrimps. - Marine Ecology Progress Series 90: 127-138.

375 Duriš, Z., Ateş, A S., Özalp, H B. \& Katağan, T.2013. New records of decapod crustaceans 376 (Decapoda: Pontoniinae and Inachidae) associated with sea anemones in Turkish waters. 377 Mediterranean Marine Science 14(Special Issue): 49-55.

378 Ďuriš, Z., Horká, I., Juračka, P.J., Petrusek, A. \& Sandford, F. 2011. These squatters are not 379 innocent: the evidence of parasitism in sponge-inhabiting shrimps. - PLoS ONE 6(7): $380 \quad$ e21987.

381 Fransen, C.H.J.M. 2002. Taxonomy, phylogeny, historical biogeography, and historical ecology 382 of the genus Pontonia Latreille (Crustacea: Decapoda: Caridea: Palaemonidae). 383 Zoologische Verhandelingen (Leiden) 336: 1-433.

384 Fransen, C.H.J.M. \& Reijnen, B.T. 2012. A second discovery of Lacertopontonia chadi Marin, 3852011 (Crustacea: Decapoda: Palaemonidae), with remarks on its systematic position. $386 \quad$ Zootaxa 3437: 43-50.

387 Gaten, E., Shelton, P.M.J. \& Herring, P.J. 1992. Regional morphological variations in the compound eyes of certain mesopelagic shrimps in relation to their habitat. - Journal of the Marine Biological Association of the United Kingdom 72: 61-75.

De Grave, S. 2001. Biogeography of Indo-Pacific Pontoniinae (Crustacea, Decapoda): a PAE analysis. - Journal of Biogeography 28(10): 1239-1253.

De Grave, S., Fransen, C.H.J.M. 2015. Let's be pals again: major systematic changes in Palaemonidae (Crustacea: Decapoda). -PeerJ 3:e1167.

De Grave, S. \& Fransen, C.H.J.M. 2011. Carideorum Catalogus: The recent species of the dendrobranchiate, stenopodidean, procarididean and caridean shrimps (Crustacea: Decapoda). - Zoologische Mededelingen, Leiden 85: 195-589. Figs 1-59.

Huebner, L.K. \& Chadwick, N.E. 2012. Patterns of cleaning behaviour on coral reef fish by the anemone shrimp Ancylomenes pedersoni. - Journal of the Marine Biological Association of the United Kingdom 92(7): 1557-1562. 
400 Hultgren, K. \& Duffy, J. 2010. Sponge host characteristics shape the community structure of their 401 shrimp associates. - Marine Ecology Progress Series 407: 1-12.

402 Hultgren, K.M. \& Duffy, J.E. 2012. Phylogenetic community ecology and the role of social 403 dominance in sponge-dwelling shrimp. - Ecology Letters 15(7): 704-13.

404 Johnson, M.L., Shelton, P.M., Gaten, E. \& Herring, P.J. 2000. Relationship of dorsoventral 405 eyeshine distributions to habitat depth and animal size in mesopelagic decapods. - Biological $406 \quad$ Bulletin 199(1): 6-13.

407 Johnson, M.L., Dobson, N.C. \& De Grave, S. 2015. External morphology of eyes and 408 Nebenaugen of caridean decapods - ecological and systematic considerations. - PeerJ. $409 \quad 3:$ e1176; DOI 10.7717/peerj.1176

410 Johnson, M.L., Shelton, P.M.J. \& Gaten, E. 2000. Temporal resolution in the eyes of marine 411 decapods from coastal and deep-sea habitats. - Marine Biology 136(2): 243-248.

412 Kawada, H., Tatsuta, H., Arikawa, K. \&Takagi, M. 2006. Comparative study on the relationship 413 between photoperiodic host-seeking behavioral patterns and the eye parameters of 414 mosquitoes. - Journal of Insect Physiology 52(1): 67-75.

415 Kou, Q., Li, X.Z., Chan, T.Y \& Chu, K.H. 2014. Divergent evolutionary pathways and host shifts 416 among the commensal pontoniine shrimps: a preliminary analysis based on selected Indo417 Pacific species. - Organisms Diversity \& Evolution 15: 369-377.

418 Limbaugh, C., Pederson, H. \& Chace, F.A. 1961. Shrimps that clean fishes. - Bulletin of Marine 419 Science 11(2): 237-257.

420 Marin, I. 2009a. A review of the pontoniine shrimp genus Rapipontonia Marin, 2007 (Decapoda: 421 Caridea: Palaemonidae), with the description of a new species from the Indo-West Pacific. 422 Zootaxa 2289: 1-17.

423 Marin, I. 2009b. Crinoid-associated shrimps of the genus Laomenes A.H. Clark, 1919 (Caridea: 424 Palaemonidae: Pontoniinae): new species and probable diversity. - Zootaxa 1971: 1-49. 425 Marin, I. \& Anker, A. 2008. A new species of Pontonia Latreille, 1829 (Crustacea, Decapoda, 426 Palaemonidae) associated with sea squirts (Tunicata, Ascidiacea) from the Pacific coast of 427 Panama. - Zoosystema 30(2): 501-515.

428 Patton, W.K. 1994. Distribution and ecology of animals associated with branching corals 429 (Acropora spp.) from the Great Barrier Reef, Australia. - Bulletin of Marine Science 55(1): $430 \quad 193-211$. 
431 R Core Team, 2013. R: A language and environment for statistical computing. R Foundation for 432 Statistical Computing. - Vienna, Austria, ISBN 3-900051-07-0. Available at: http://www.r433 project.org.

434 Snyder, A.W. 1979. Physics of vision in compound eyes. Pp 225-313 in: H. Autrum, (eds).

435 Comparative Physiology and Evolution of Vision in Invertebrates A: Invertebrate 436 photoreceptors. - Springer-Verlag, Berlin.

437 Stavenga, D.G. 2003. Angular and spectral sensitivity of fly photoreceptors. II. Dependence on 438 facet lens F-number and rhabdomere type in Drosophila. - Journal of Comparative 439 Physiology A, 189(3): 189-202.

440 Stavenga, D.G. \& Hardie, R.C. 1989. Facets of vision. - Springer-Verlag, London.

441 Stella, J.S. Pratchett, M.S., Hutchings, A.P. \& Jones, G.P. 2011. Coral-associated invertebrates: 442 diversity, ecological importance and vulnerability to disturbance. - Oceanography and 443 Marine Biology: An annual review 49: 43-104.

444 Zuur, A.F., Ieno, E.N. \& Elphick, C.S. 2010. A protocol for data exploration to avoid common 445 statistical problems. - Methods in Ecology and Evolution 1(1): 3-14. 
1

Figure 1. Mean relative eye diameter (standardised by post-orbital carapace length) for 83 species of Pontoniinae associated 8 host-symbiont groupings.

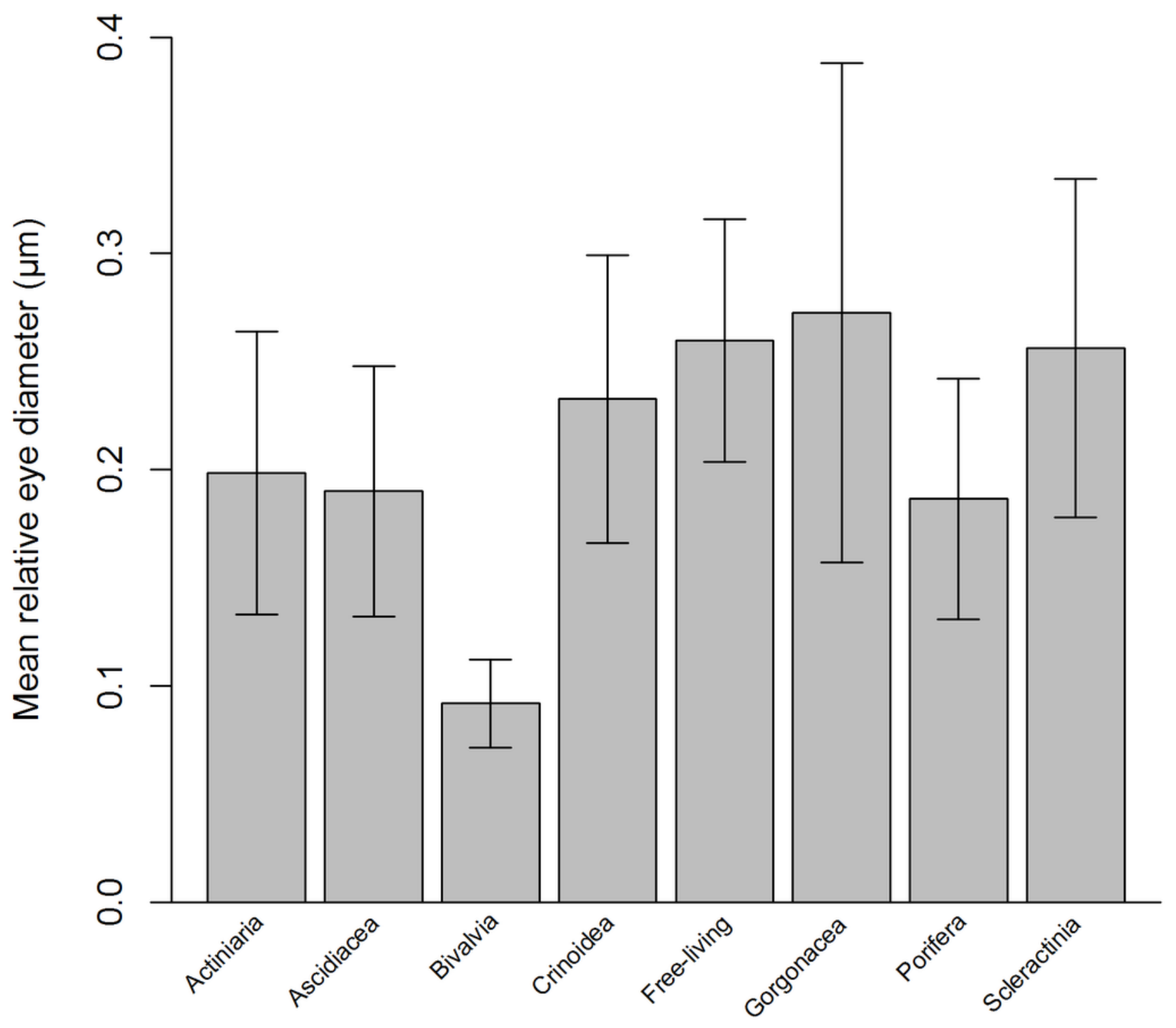

Host-symbiont grouping 
2

Figure 2. Median eye parameter for 83 species of Pontoniinae from 8 host-symbiont groupings. Significant differences are represented by hosts possessing the same letter A-I (Tukey HSD $P<0.05$ ).

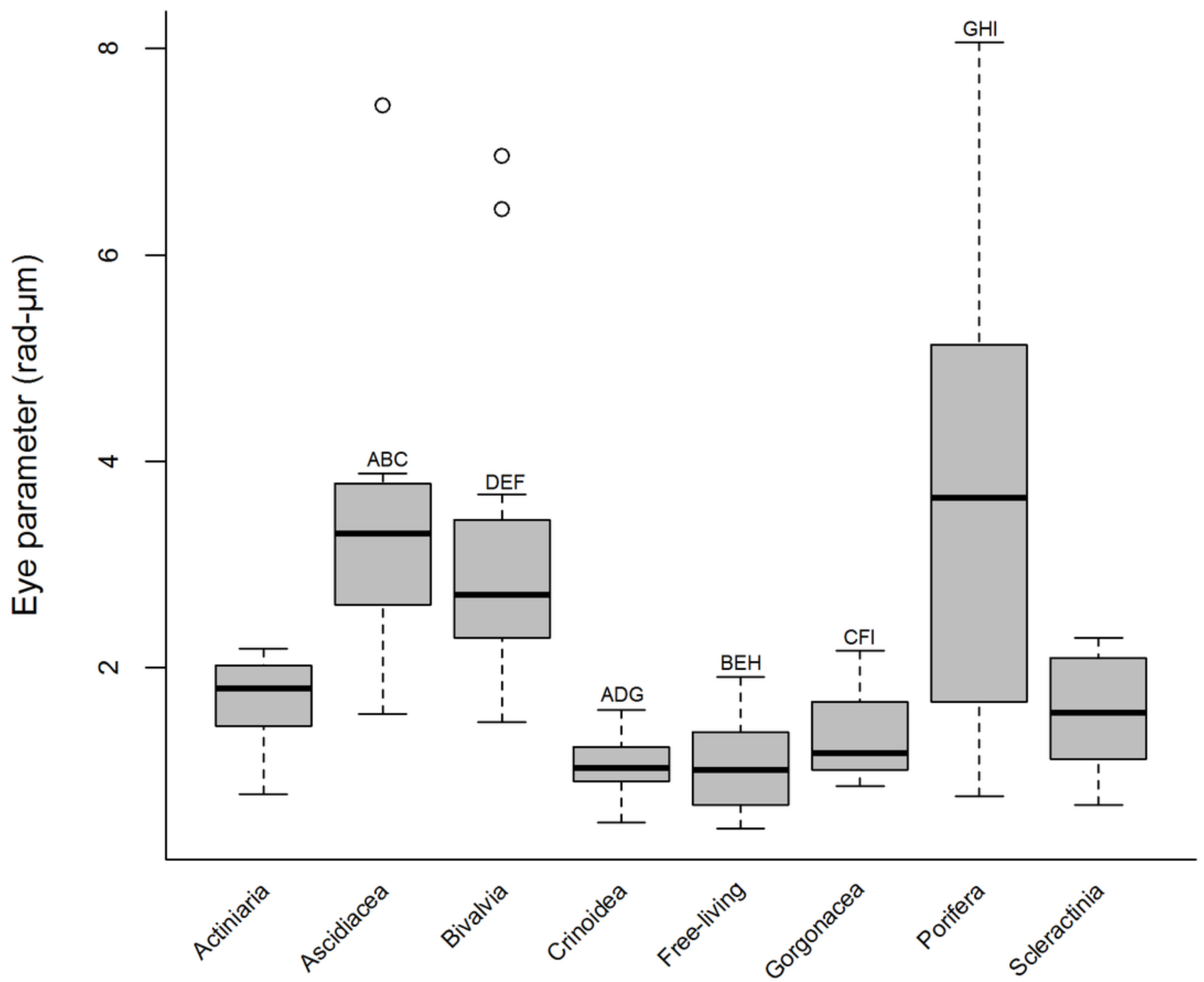

Host-symbiont groupings 
3

Figure 3. Percentage occurrence of the nebenauge for 83 species of Pontoniinae from 8 host-symbiont groupings.

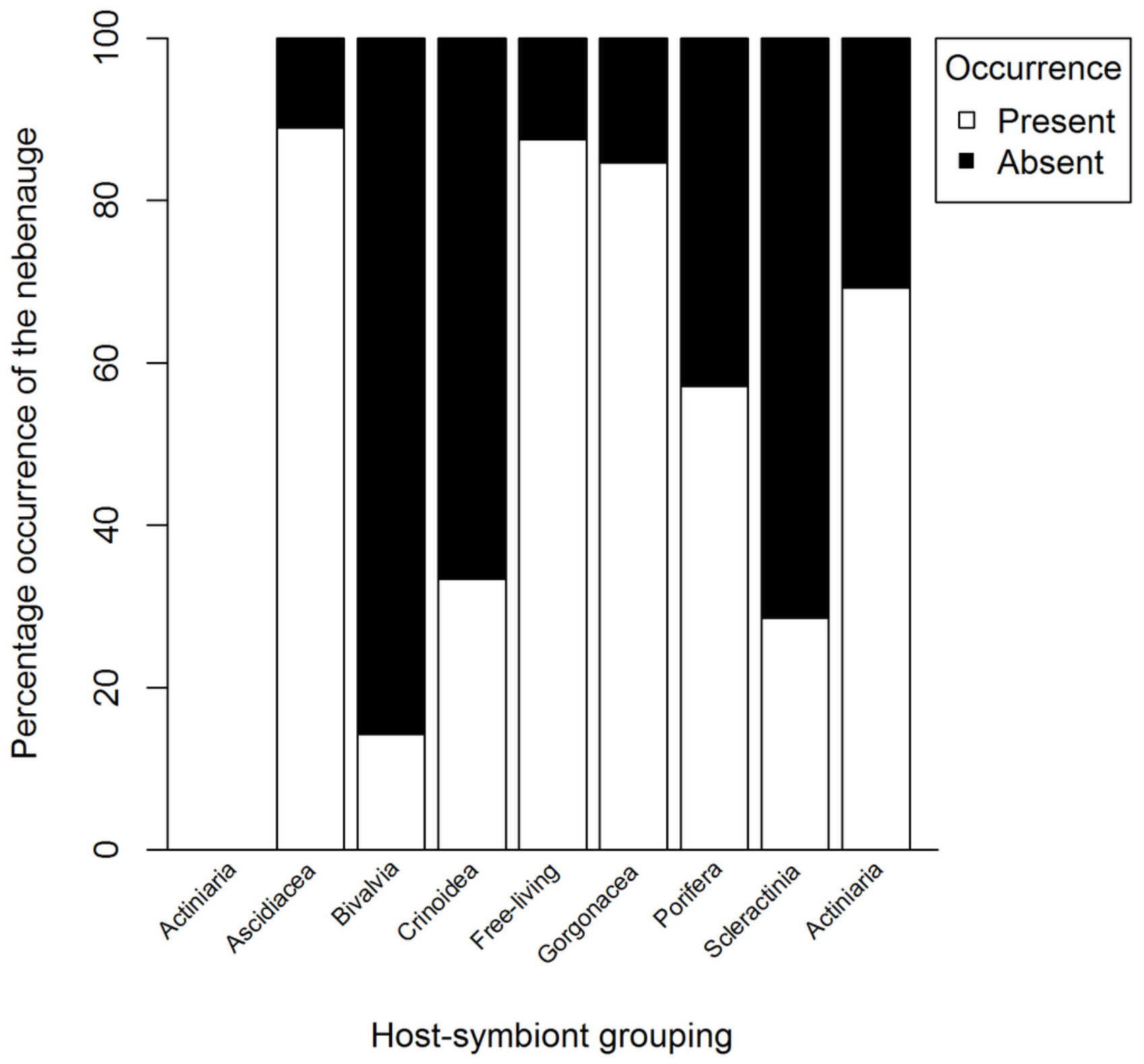




\section{4}

Figure 4. Morphological variation demonstrated by the DFA scores (first and second root only) of all 83 species of pontoniine shrimps (grey circles) displaying the positioning of the centroids for each of the 8 hosts-symbionts groups.

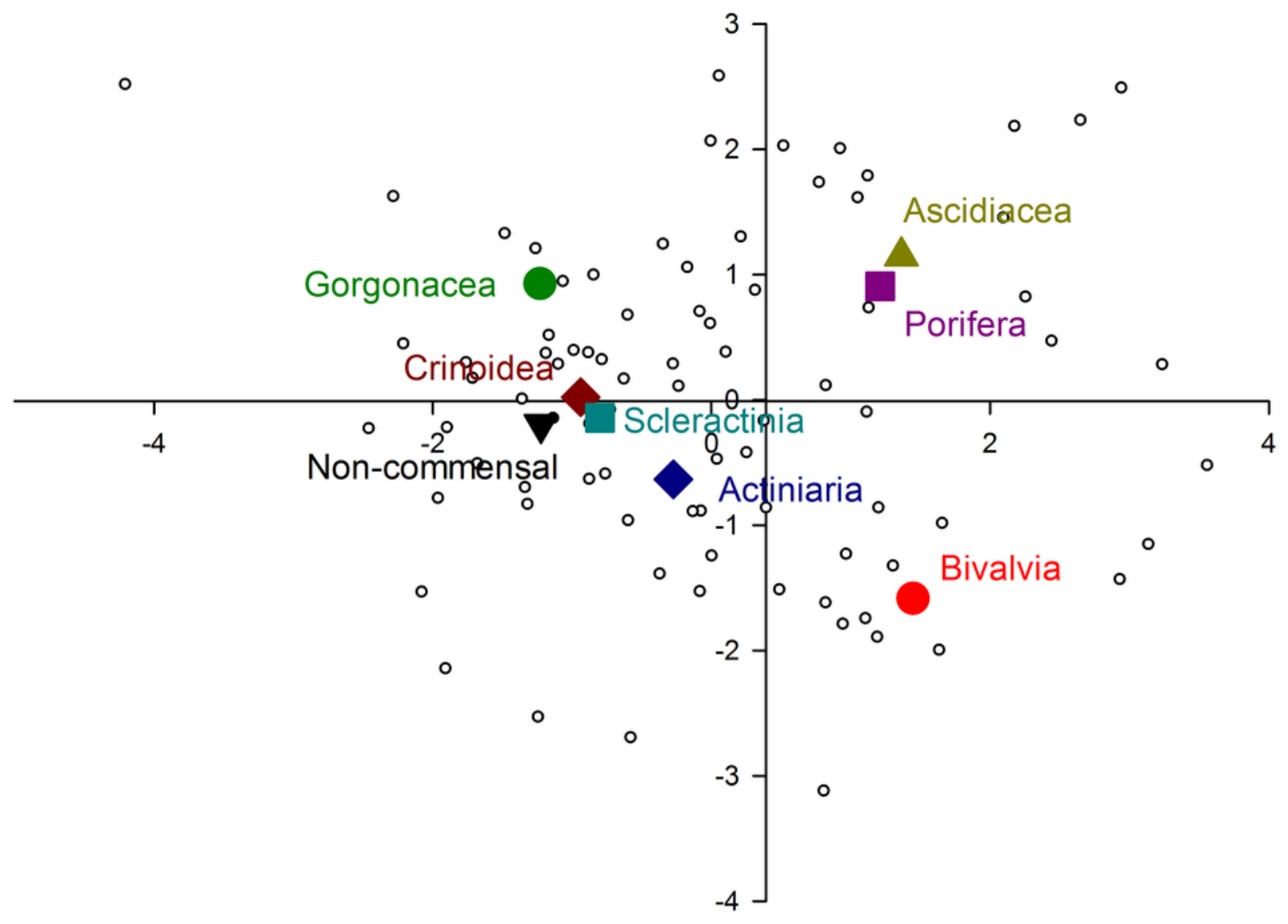




\section{5}

Figure 5. Morphological variation demonstrated by the DFA scores (first and second root only) of Ascidiacea associates.

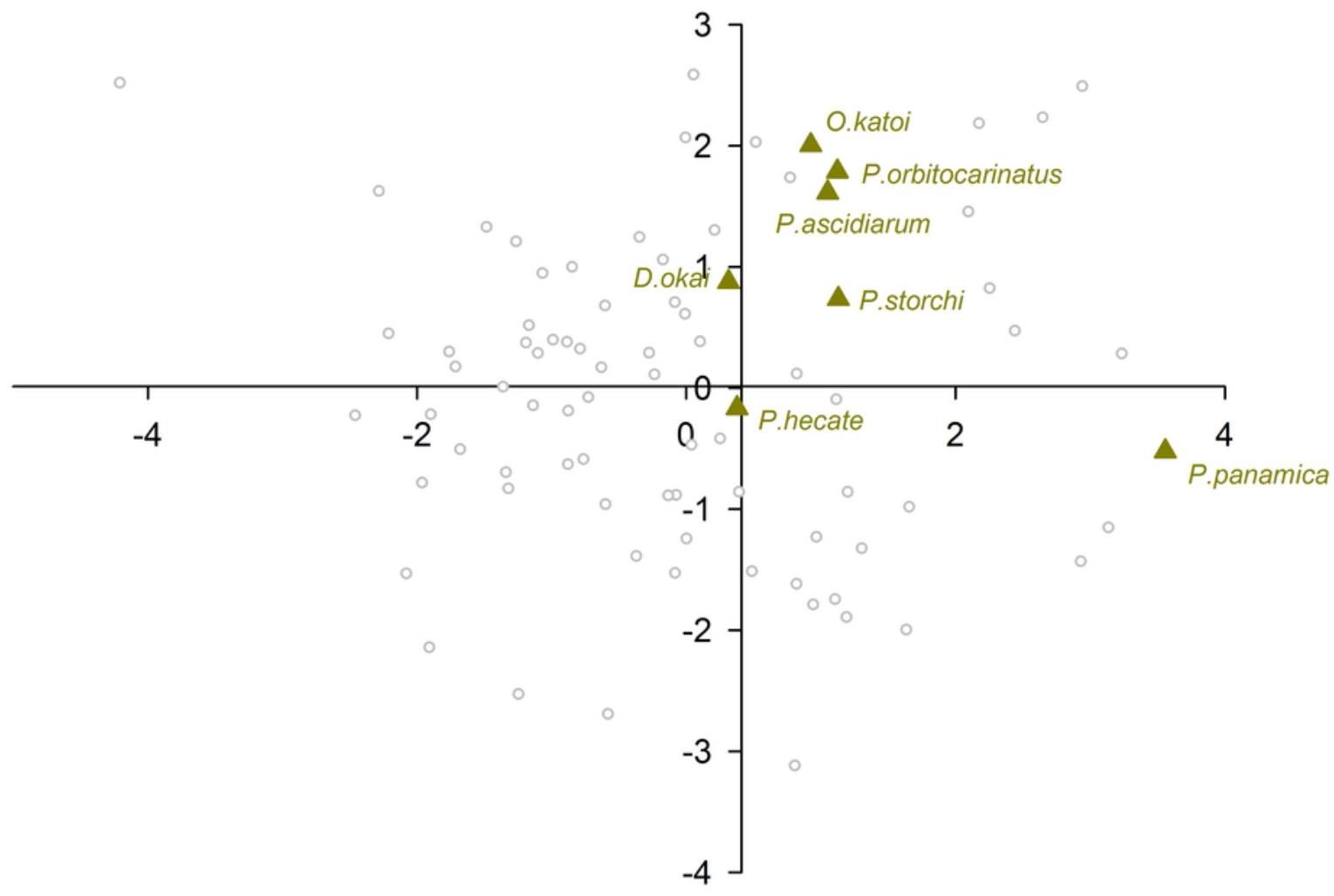




\section{6}

Figure 6. Morphological variation demonstrated by the DFA scores (first and second root only) of Porifera associates.

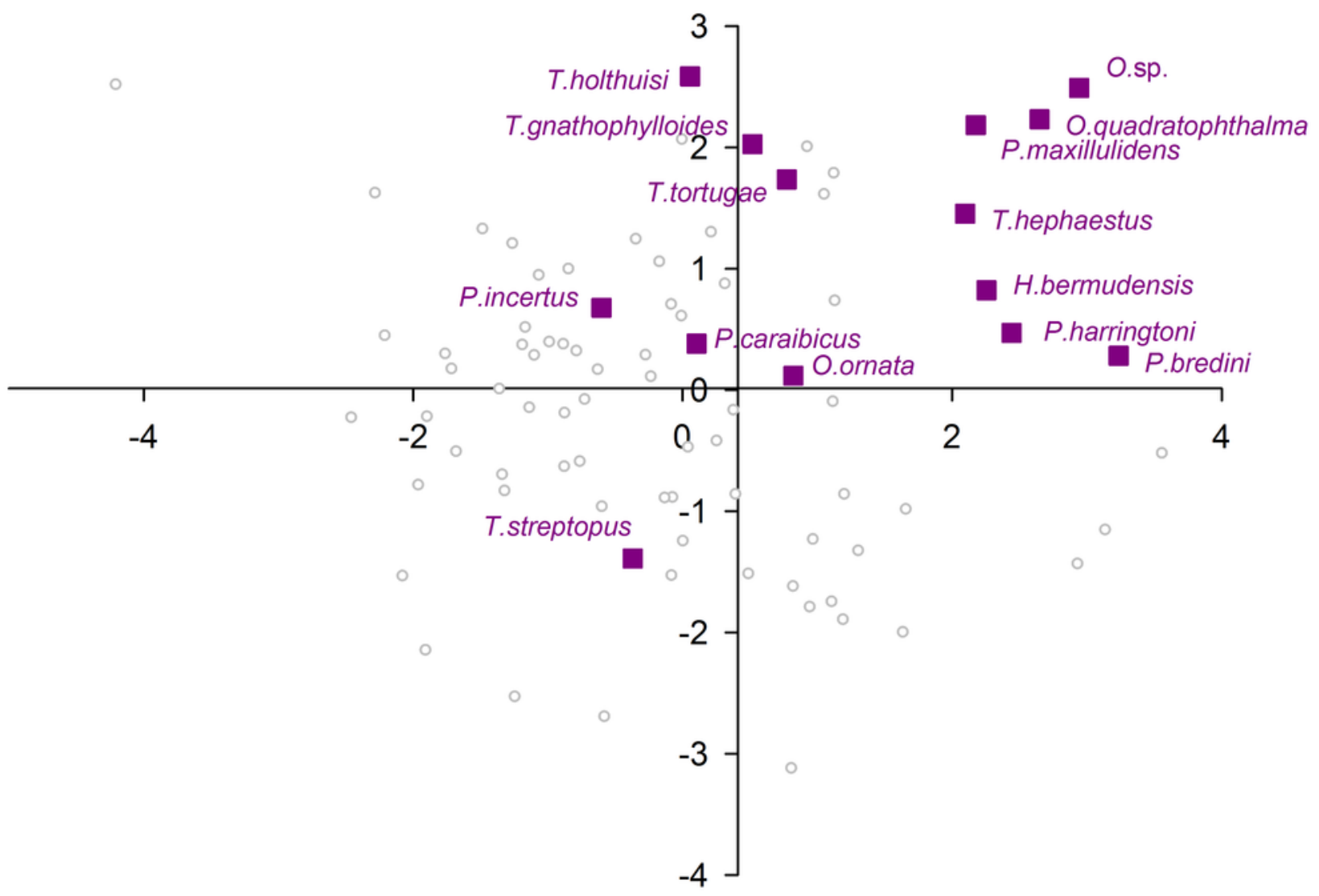




\section{7}

Figure 7. Morphological variation demonstrated by the DFA scores (first and second root only) of Bivalvia associates.

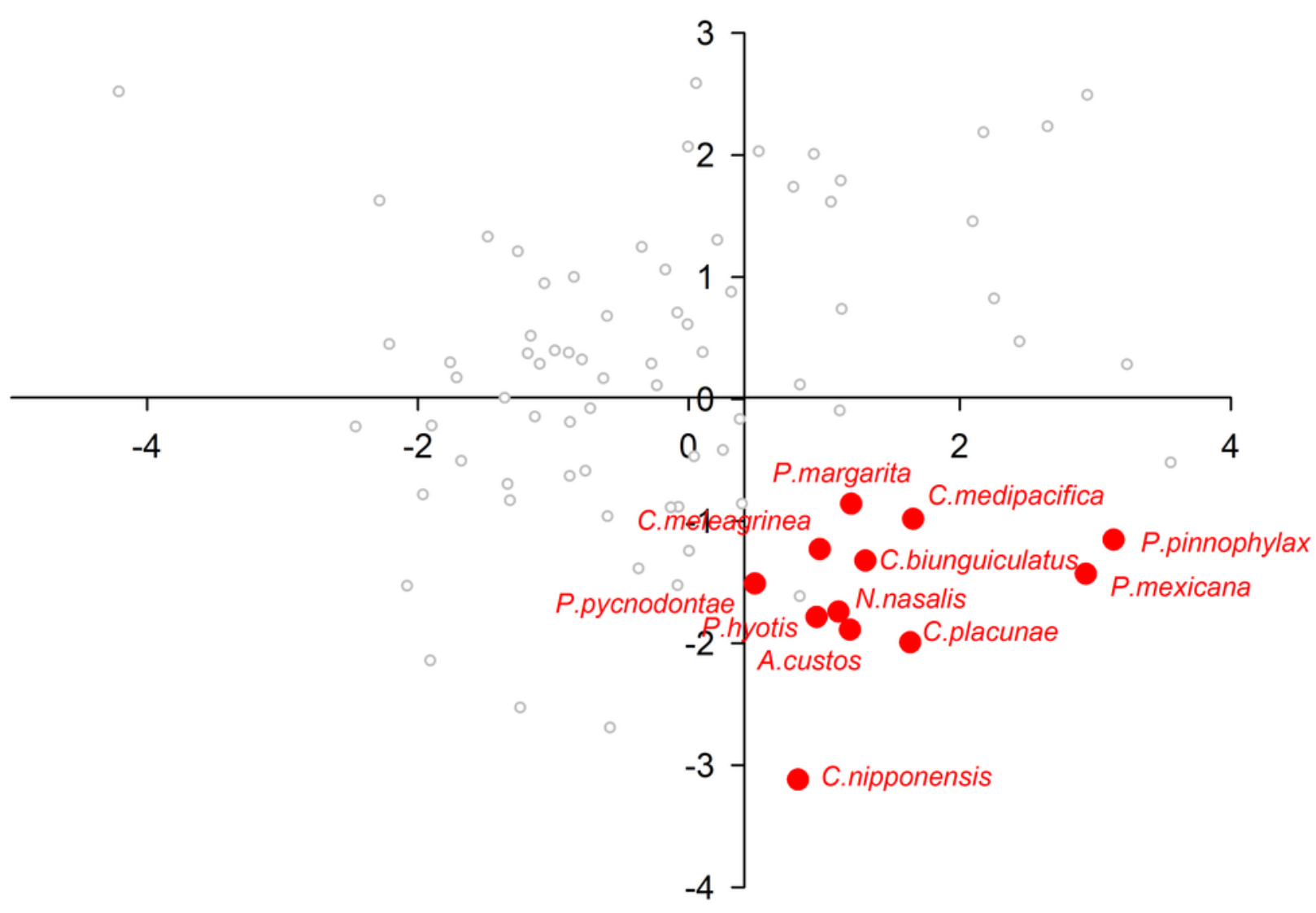


8

Figure 8. Morphological variation demonstrated by the DFA scores (first and second root only) of Crinoidea associates.

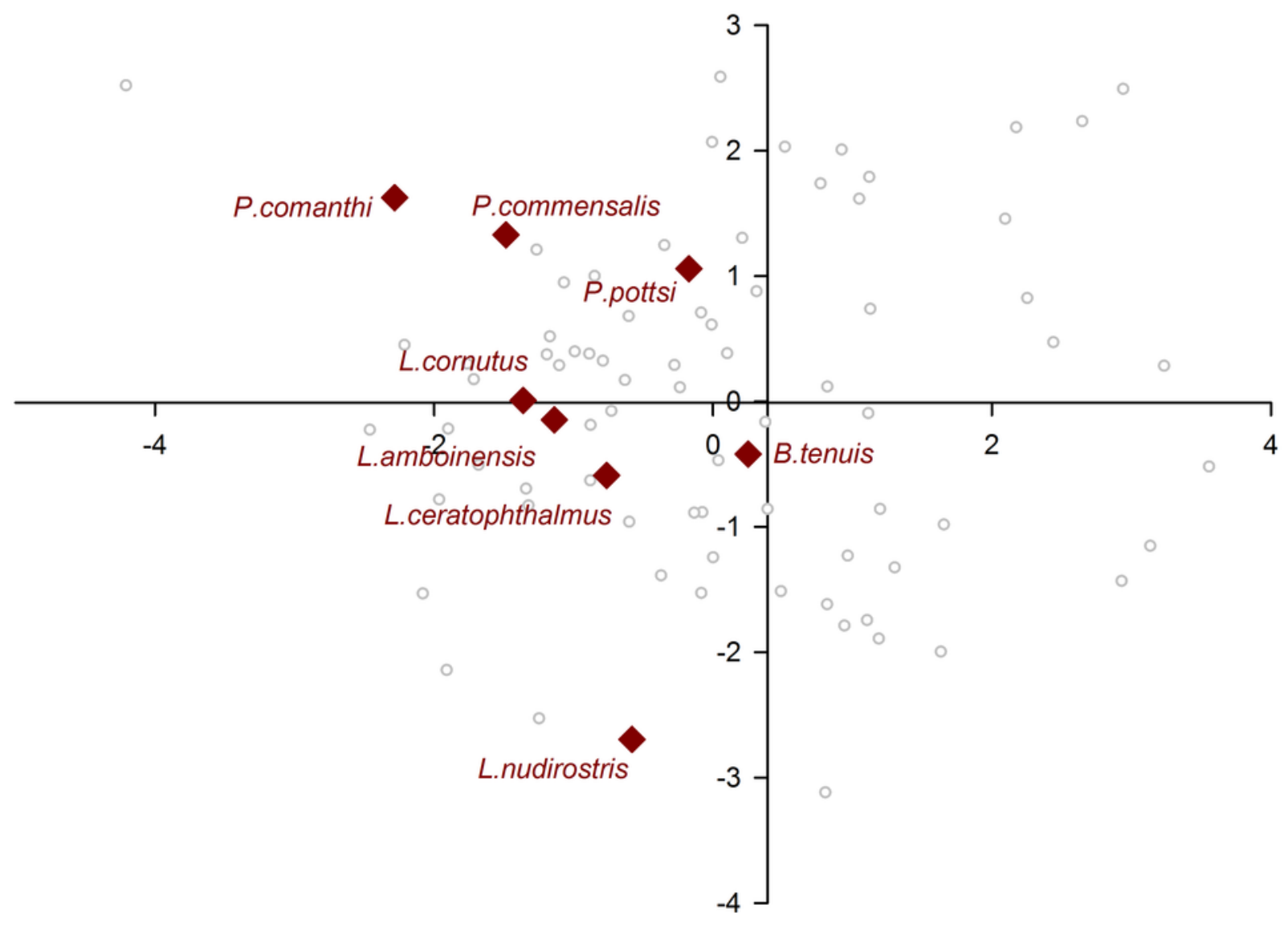


9

Figure 9. Morphological variation demonstrated by the DFA scores (first and second root only) of Scleractinia associates.

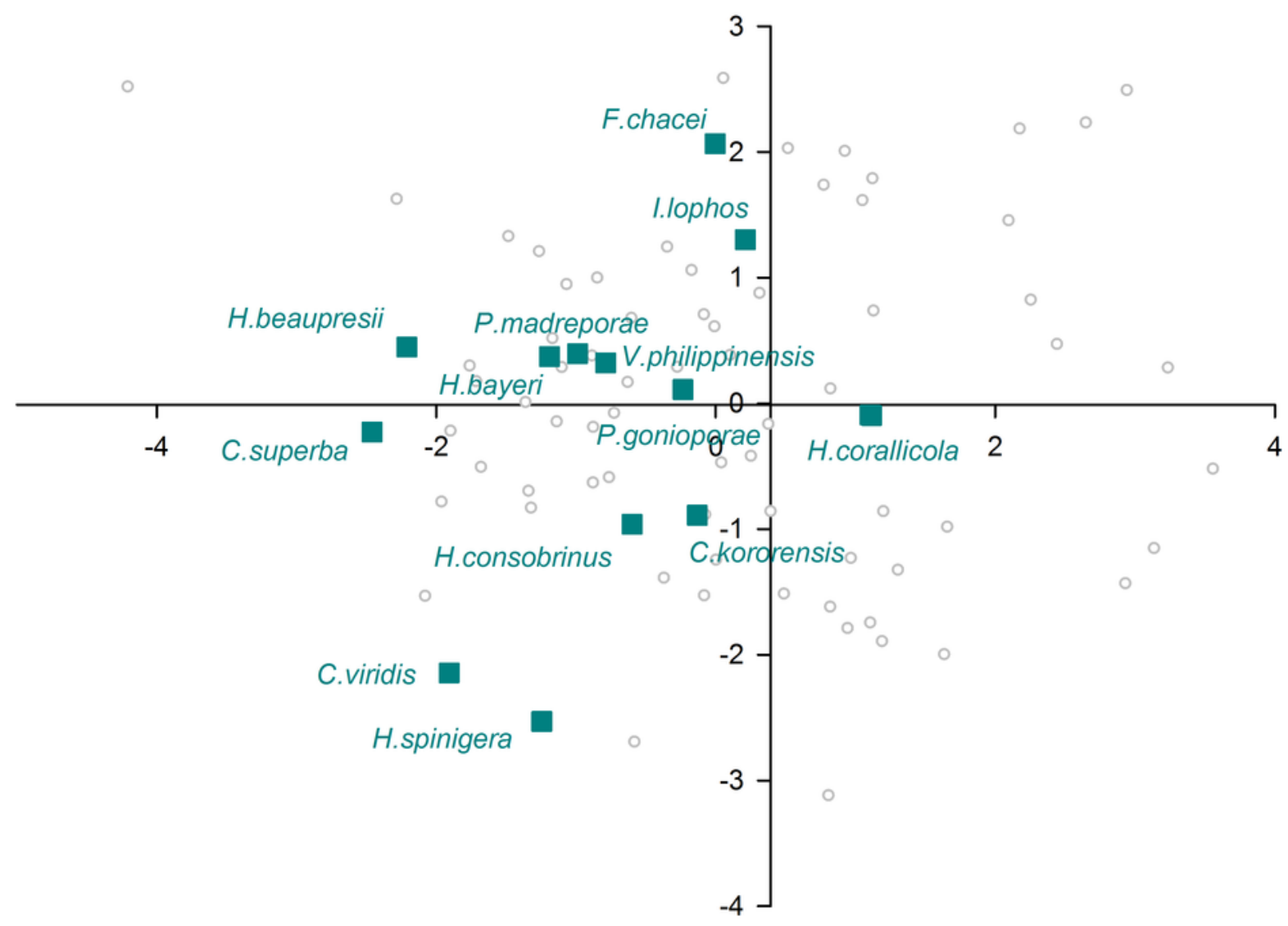




\section{0}

Figure 10. Morphological variation demonstrated by the DFA scores (first and second root only) of non-commensal species.

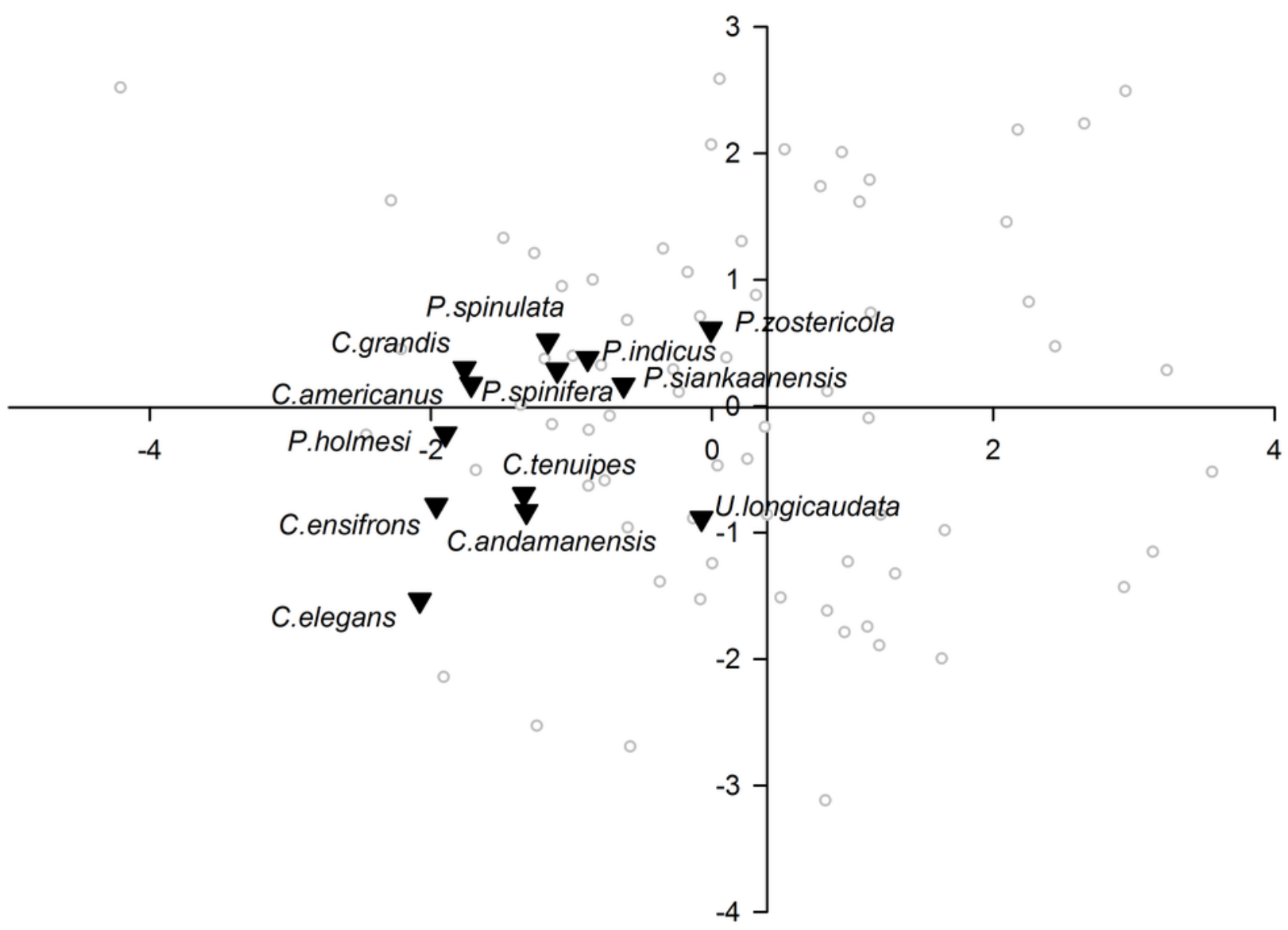


11

Figure 11. Morphological variation demonstrated by the DFA scores (first and second root only) of Gorgonacea associates.

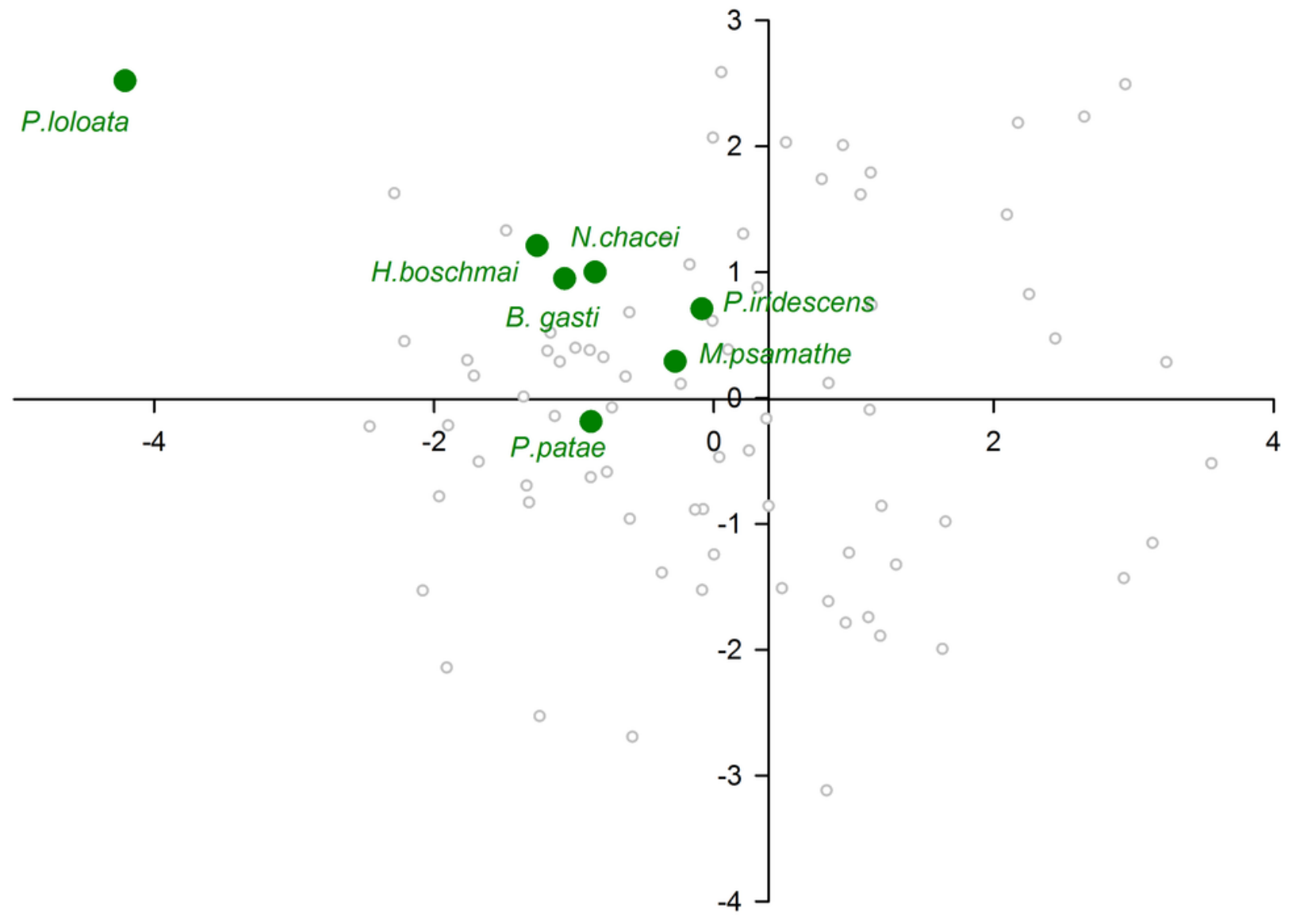


12

Figure 12. Morphological variation demonstrated by the DFA scores (first and second root only) of Actiniaria associates.

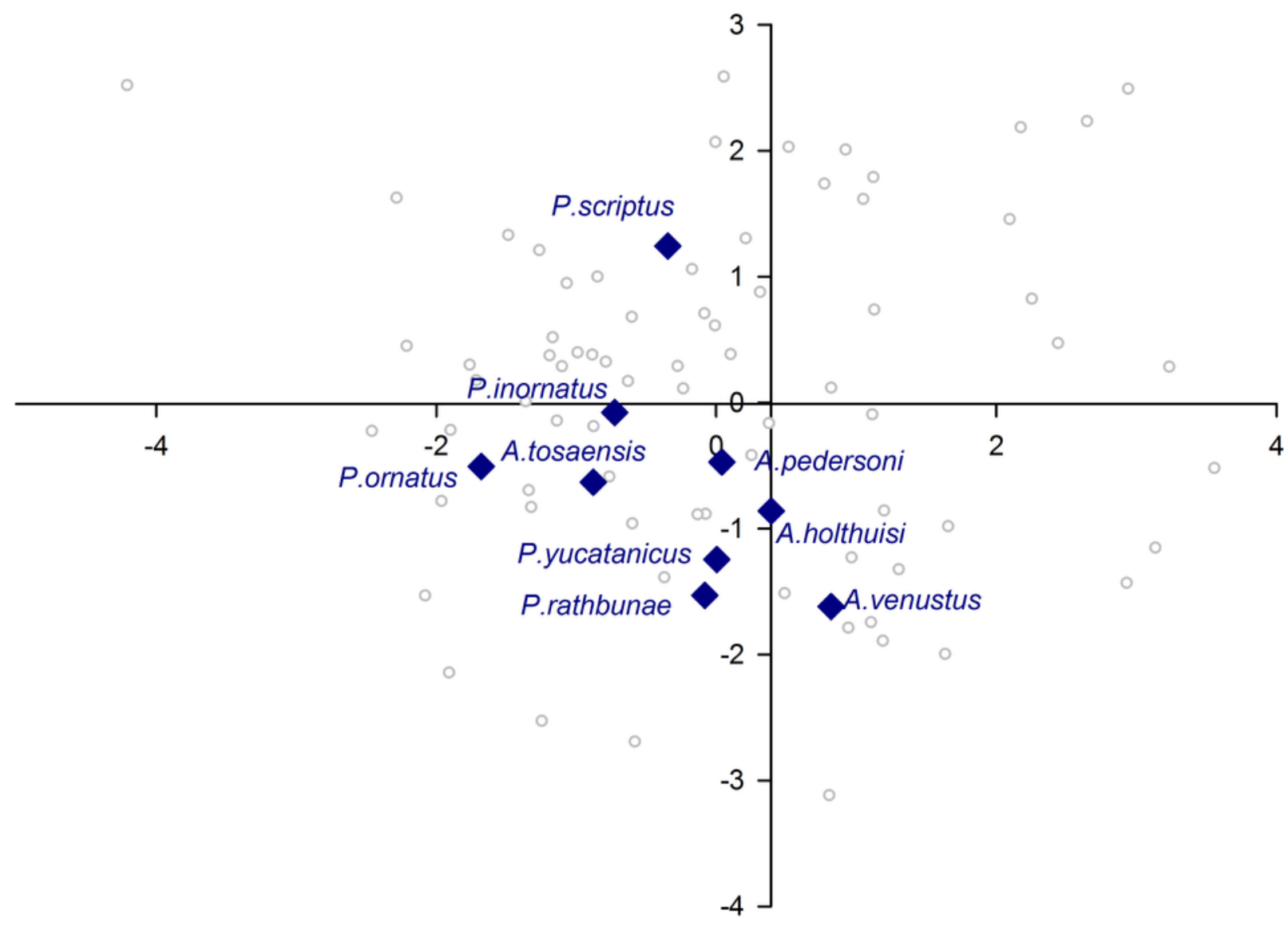




\section{Table 1 (on next page)}

Table 1. Summary statistics for DFA analysis. 
1 Table 1. Summary statistics for DFA analysis

2

$\begin{array}{llllllc} & \text { Eigenvalue } & \begin{array}{c}\text { \% of } \\ \text { variance }\end{array} & \begin{array}{c}\text { Cumulative } \\ \%\end{array} & \begin{array}{l}\text { Canonical } \\ \text { correlation }\end{array} & \begin{array}{c}\text { Wilks's } \\ \lambda\end{array} & \begin{array}{c}P \\ \text { value }\end{array} \\ \text { Root 1 } & 1.436 & 59.1 & 59.1 & 0.768 & 0.194 & <0.005 \\ \text { Root 2 } & 0.864 & 35.5 & 94.6 & 0.681 & 0.473 & <0.005 \\ \text { Root 3 } & 0.090 & 3.7 & 98.4 & 0.288 & 0.882 & 0.482 \\ \text { Root 4 } & 0.040 & 1.6 & 100 & 0.196 & 0.962 & 0.561\end{array}$

3 


\section{Table 2 (on next page)}

Table 2. Structure matrix of discriminant loadings, with the largest absolute correlation between each variable and any discriminant function indicated by *. All variables were entered simultaneously. 
1 Table 2. Structure matrix of discriminant loadings, with the largest absolute correlation between

2 each variable and any discriminant function indicated by *. All variables were entered

3 simultaneously.

4

$\begin{array}{lll} & \text { Function 1 } & \text { Function } 2 \\ \text { ArcsinFD } & 0.808^{*} & 0.482 \\ \text { EP } & 0.718^{*} & 0.166 \\ \text { ArcsinED } & -0.657^{*} & 0.481 \\ \text { ES-DBES } & -0.158 & -0.695^{*}\end{array}$

5 


\section{Table 3(on next page)}

Table 3. DFA Classification matrix, showing number of species correctly and incorrectly classified into a priori defined groups, expressed as a percentage of within group species numbers. 
Table 3. DFA Classification matrix, showing number of species correctly and incorrectly classified into a priori defined groups, expressed as a percentage of within group species numbers.

\section{DFA classification}

\begin{tabular}{|c|c|c|c|c|c|c|c|c|}
\hline & Actiniaria & Ascidiacea & Bivalvia & Crinoidea & Non-commensal & Gorgonacea & Porifera & Scleractinia \\
\hline Actiniaria & 22.2 & - & 11.1 & 11.1 & 22.2 & - & - & 33.3 \\
\hline Ascidiacea & 14.3 & - & 14.3 & - & - & - & 71.4 & - \\
\hline Bivalvia & - & - & 100.0 & - & - & - & - & - \\
\hline Crinoidea & 25.0 & - & - & 12.5 & 12.5 & 37.5 & - & 12.5 \\
\hline Non-commensal & 7.7 & - & - & 15.4 & 61.5 & - & - & 15.4 \\
\hline Gorgonacea & - & - & - & 28.6 & 14.3 & 42.9 & - & 14.3 \\
\hline Porifera & 7.1 & - & - & 14.3 & - & - & 78.6 & - \\
\hline Scleractinia & 15.4 & - & - & 7.7 & 15.4 & - & 23.1 & 38.5 \\
\hline
\end{tabular}

